Theory: State of the Art Review [Invited Paper]

\title{
Personality Trait Stability and Change
}

\author{
Wiebke Bleidorn $^{1}$ (D) , Christopher J. Hopwood ${ }^{1}$ (D) , Mitja D. Back ${ }^{2}$ (D) , \\ Jaap J. A. Denissen ${ }^{3}$ (D) , Marie Hennecke ${ }^{4}$ (D) , Patrick L. Hill ${ }^{5}$ (D) , Markus Jokela ${ }^{6}$ (D) , \\ Christian Kandler $^{7}$ (D) , Richard E. Lucas ${ }^{8}$ (D) , Maike Luhmann ${ }^{9}$ (D) , Ulrich Orth ${ }^{10}$ (D) , \\ Brent W. Roberts ${ }^{11}$ (D) , Jenny Wagner ${ }^{12}$ (D) , Cornelia Wrzus ${ }^{13}$ (D) , \\ Johannes Zimmermann ${ }^{14}$
}

[1] Department of Psychology, University of California Davis, Davis, CA, USA. [2] Department of Psychology, University of Münster, Münster, Germany. [3] Department of Psychology, Utrecht University, Utrecht, the Netherlands.

[4] Department of Psychology, University of Siegen, Siegen, Germany. [5] Department of Psychological and Brain Sciences, Washington University in St. Louis, St. Louis, MO, USA. [6] Department of Psychology and Logopedics, University of Helsinki, Helsinki, Finland. [7] Department of Psychology, University of Bremen, Bremen, Germany. [8] Department of Psychology, Michigan State University, East Lansing, MI, USA. [9] Department of Psychology, Ruhr University Bochum, Bochum, Germany. [10] Department of Psychology, University of Bern, Bern, Switzerland. [11] Department of Psychology, University of Illinois, Urbana, IL, USA. [12] Department of Psychology, University of Hamburg, Hamburg, Germany. [13] Department of Psychology, University of Heidelberg, Heidelberg, Germany. [14] Department of Psychology, University of Kassel, Kassel, Germany.

Personality Science, 2021, Vol. 2, Article e6009, https://doi.org/10.5964/ps.6009

Received: 2021-01-28 • Accepted: 2021-04-20 • Published (VoR): 2021-06-21

Handling Editor: John F. Rauthmann, Bielefeld University, Bielefeld, Germany

Reviewing: Round 1 - David Funder; Anonymous \#1. No open reviews are available

Corresponding Author: Wiebke Bleidorn, Department of Psychology, University of California Davis, One Shields Avenue, Davis, CA 95616, USA. E-mail: wiebkebleidorn@gmail.com

\section{Abstract}

Personality traits continue to change throughout the lifespan. However, we still know little about when, why, and how personality traits change. In this paper, we review the current state of scientific evidence regarding the nature, sources, and processes of personality trait stability and change. We revisit past disputes over the relative importance of genetic and environmental influences, discuss studies on life events and personality trait development, and summarize theory and research on personality change processes. In doing so, we derive general principles of personality trait development, highlight limitations of past research, and present the broad outlines 
for future research on personality trait development, with a particular emphasis on relevant methodological issues and conceptual challenges.

\section{Keywords}

personality development, longitudinal, Big Five, lifespan, personality processes, traits

\section{Relevance Statement}

The power of personality traits in predicting consequential outcomes is well established. The recognized importance of personality has raised questions about their malleability: Given that traits predict important outcomes, can we shape or change them? Traditionally, traits have been conceptualized as static entities that are difficult or even impossible to change. For a long time, the view has led to a gridlock in research on personality change. However, there now is robust evidence that personality traits are dynamic characteristics that continue to change across the lifespan. Equipped with this evidence, we can now begin to address questions about the stability and malleability of personality traits. In this paper, we review research on the lifespan development of personality traits, highlight open questions, and present the outlines for a novel framework for studying personality development that aims to address the gaps identified in the literature, with a particular emphasis on relevant methodological complexities and conceptual challenges. In doing so, we argue that progress in this field will likely depend on more collaborative efforts of researchers who join resources and expertise to study personality change in large-scale longitudinal studies.

\section{Key Insights}

- Personality traits change in the direction of greater maturity.

- People differ in the rate, timing, and direction of personality trait change.

- Open questions remain about the specific sources and processes underlying personality trait change.

- Future directions include rigorous longitudinal studies of sources and processes methods in diverse samples.

The power of personality traits in predicting consequential outcomes is well-established (Roberts et al., 2007; Soto, 2021). People high in traits such as conscientiousness and emotional stability often fare better than those who score low in these traits across a wide variety of life domains. However, researchers outside of personality psychology have sometimes dismissed the importance of such findings because they often assumed that personality traits are so stable that these associations provide very little practical insight into how to improve people's lives. If it is impossible to increase conscientiousness, what good is it to know that having higher levels of conscientiousness would lead to better outcomes? 
A growing body of research now shows that the assumption that personality traits cannot change is wrong. Personality traits continue to change throughout the lifespan (Roberts \& DelVecchio, 2000; Roberts et al., 2006), sometimes in response to environmental changes (Bleidorn et al., 2018), including purposeful interventions (Roberts et al., 2017). These findings provide a solid foundation on which researchers can develop their understanding of the sources and processes underlying personality trait development. However, we still know little about when, why, and how personality traits change. These gaps can be traced back to both theoretical and methodological challenges associated with the study of personality trait stability and change.

In this paper, we review the current state of evidence regarding the nature, sources, and processes of stability and change in personality traits. In doing so, we aim to derive general principles of trait development, highlight unanswered questions, and discuss recommendations for future studies on personality trait development that aim to address the gaps identified in the literature, with a particular emphasis on methodological complexities and conceptual challenges. In doing so, we draw on ideas discussed in previous papers by this group (Bleidorn et al., 2019; Bleidorn et al., 2020; Wagner et al., 2020) and define personality traits as relatively enduring patterns of thoughts, feelings, strivings, and behaviors that distinguish individuals from each other (Allport, 1961). We organize our review in reference to the Big Five - openness to experience, conscientiousness, extraversion, agreeableness, and neuroticism/emotional stability (John \& Srivastava, 1999) - which offer a useful structure to organize research on trait development while providing a viable balance between conceptual breadth, descriptive fidelity, and generalizability across samples and measures (Costa et al., 2019). We note that there are traits that cannot be easily placed in a Big Five structure (e.g., Ashton \& Lee, 2020) and, of course, there is more to personality than traits. Recent handbooks on personality development offer a more comprehensive perspective on the stability and change of other personality constructs, such as life narratives, motives, and values (e.g., McAdams et al., 2018; Specht, 2017).

\section{Why Should We Care About Personality Trait Stability and Change?}

Traditionally, the field has emphasized the stable nature of traits (McCrae \& Costa, 2008). Part of this emphasis on stability can be traced back to claims that personality traits are of little utility in predicting behavior which is better explained by stable situational pressures. As a reaction to these claims, the field of personality psychology focused large efforts on showing that traits are stable and powerful predictors of a broad range of important life outcomes (Ozer \& Benet-Martinez, 2006; Roberts et al., 2007; Soto, 2021). An unintended side effect of these efforts, however, was a relative neglect of research 
on the more dynamic aspects of traits. This ultimately contributed to the common but inaccurate belief that traits are static entities and, as such, practically unchangeable.

This belief is difficult to square with existing evidence. As we will describe below, personality traits continue to change across the lifespan. Critically, recent research has also demonstrated that people differ in their personality trajectories, and that such differences are meaningfully related to change in various life domains. For example, increases in conscientiousness and decreases in neuroticism have been associated with improvements in mental health outcomes (Wright et al., 2015).

In sum, personality traits are sufficiently broad and stable to predict a wide range of important life outcomes, but also malleable enough to potentially serve as powerful yet largely ignored targets for interventions (Bleidorn et al., 2019). The increased recognition of personality traits as potential targets for interventions has spurred research on the nature, sources, and processes of personality stability and change. With this evidence at hand, we can now address important questions about the stability of and change in personality traits.

\section{What Do We Know About Personality Trait Stability and Change?}

There are different ways to frame and answer questions about personality trait development. Here, we focus on three specific questions that are inherently connected to different research designs and indices of change: How stable are personality traits? How do traits develop across the lifespan? And, how do people differ in their personality trajectories? Answers to each of these questions provide complementary but non-overlapping information about personality stability and change.

\section{How Stable are Personality Traits?}

The stability of traits is often operationalized as rank-order stability and can be expressed as test-retest correlation between two assessments, indicating the degree to which differences between people are stable over time. Questions about the rank-order stability of traits are the heart of research on personality development as evidenced by multiple reviews and meta-analyses on this topic (e.g., Fraley \& Roberts, 2005; Roberts \& DelVecchio, 2000). These works converge on three broad conclusions.

First, personality traits are moderately stable over time with rank-order stabilities ranging between .4 to .6 over 10-year time lags, and decreasing rank-order stabilities over longer time lags (Fraley \& Roberts, 2005). Despite time-related decreases, recent research supports the stability of traits even at very long intervals. For instance, Damian et al. (2019) found the rank-order stabilities of self-reported personality traits to lie around .2 across 30 or more years. A second finding to emerge from this literature is that 
personality traits increase in rank-order stability over the course of young and middle adulthood, and peak around age 60, suggesting that traits are most prone to change in young and potentially also old adulthood (Lucas \& Donnellan, 2011). Third, the levels of rank-order stability never reach unity (even after controlling for rater specificity and random measurement error; Kandler et al., 2010), suggesting lifelong plasticity of personality traits. In other words, personality traits can and do change at any age throughout the lifespan.

In summary, the literature on rank-order stability provides strong evidence that individual differences in personality traits are stable across many decades. Stability is highest during middle adulthood and relatively lower during young adulthood and potentially also old age. Notably, stability is only modest over longer intervals, leaving room for personality trait change throughout the lifespan.

\section{How Do Personality Traits Develop Across the Lifespan?}

Evidence for the stability of traits provides an important but incomplete perspective on personality development. A complementary question concerns the mean-level change of traits in a population. Mean-level change can be expressed as standardized mean-level difference across time or age groups and reflects the degree to which trait levels decrease or increase among all people in a population, on average.

A large body of research provided converging evidence that personality traits undergo substantial mean-level changes throughout the lifespan, particularly during young adulthood (Roberts et al., 2006). Specifically, young adults tend to increase in trait levels that reflect greater psychological maturity such as emotional stability, conscientiousness, and agreeableness. This pattern has been referred to as the maturity principle of personality development and found to generalize across cohorts, genders, and, to a certain degree, also across samples from different cultures (Bleidorn et al., 2013; Bleidorn et al., 2019).

Over the past decade, a burgeoning literature has focused on personality trait development in adolescence. Results from this body of work indicated a temporary dip in socially relevant traits such as conscientiousness, extraversion, and agreeableness during adolescence (Denissen et al., 2013; Soto, 2016). This trend - often referred to as disruption hypothesis - has been replicated in cross-sectional and longitudinal studies using both self-reports and parents' reports (Soto \& Tackett, 2015).

In contrast to the budding literatures on personality trait development in adolescence and young adulthood, considerably fewer studies have examined samples of middle-aged and older adults. Although the period from middle age onwards is characterized by more stability than earlier life stages, there is growing evidence that personality traits continue to develop throughout these life stages (e.g., Kandler et al., 2015). Some - but not all - of these studies suggest that the personality maturation trends that characterize young and middle adulthood are reversed in late adulthood, as indicated by mean-level decreases 
in emotional stability, agreeableness, extraversion, and conscientiousness that appear to occur during very old age (Graham et al., 2020; Mõttus et al., 2012).

\section{How Much Do People Differ in Their Personality Trait Development?}

Not everyone changes in the same direction or to the same degree. Questions about individual differences in change focus on how individuals' personality trajectories conform to vs. deviate from the overall population trends of mean-level change. For instance, although most people increase in levels of conscientiousness during the transition from adolescence to early adulthood, some individuals remain stable or even report significant decreases in this trait domain (Schwaba \& Bleidorn, 2018). A reliable assessment of individual differences in change is a necessary condition for studying the correlates and causes of development.

Although meta-analytic evidence is lacking, there is robust evidence from large-scale population-based studies for substantial individual differences in change throughout the lifespan and across trait domains (Graham et al., 2020). As with rank-order and meanlevel change, individual differences in personality trait change appear to be most pronounced during young adulthood (Schwaba \& Bleidorn, 2018) providing further support for theories that consider this life stage as a critical period for personality development (Bleidorn et al., 2020).

\section{Summary}

The large and growing body of research on personality trait stability and change has shown that a) traits generally increase in rank-order stability, b) trait levels can and do change at any age throughout the lifespan, with c) young adulthood is a particularly important time for personality trait change. There is further robust evidence that $d$ ) the average person's personality traits change in the direction of greater psychological maturity across adulthood and that e) people differ in the rate, timing, and direction of trait change. Taken together, these findings paint a clear picture of personality traits as dynamic characteristics of persons that are both moderately stable and malleable across the lifespan.

\section{Lingering Questions About Personality Trait Development}

In contrast to the broad consensus regarding the nature of personality trait development, we still know little about the sources that contribute to stability and change in personality traits and even less about the process underlying such changes (Specht et al., 2014; Wagner et al., 2020). In this section, we review theory and existing research on potential 
sources of personality trait development, discuss process models of personality trait change, and highlight limitations and open questions in these lines of research.

\section{What Drives Personality Trait Stability and Change?}

Historically, the field has vacillated between positions that emphasized the importance of either genetic or environmental influences on personality trait stability and change. During the past two decades, several longitudinal behavioral genetic studies have tested the role of genetic and environmental influences on individual differences in personality trait stability and change (Briley \& Tucker-Drob, 2014). The accumulated evidence converges on the conclusion that both genetic and environmental influences contribute to both stability and change in personality traits. Yet, little is known about the specific genetic pathways or the specific environmental sources that underlying stability and change in personality traits (Wagner et al., 2020).

Large-scale genome-wide association studies have not led to the much-hoped for breakthroughs in our understanding of the genetic foundations of personality trait development. Rather, this line of work highlighted that any effects of single gene variants are extremely small and likely depend on other genetic effects as well as the environment in which they are expressed. Similarly, the effects of environmental experiences (e.g., specific life events) tend to be small and notoriously difficult to replicate (Bleidorn et al., 2020).

A large body of research has focused on the potential effects of life events on personality trait change. Overall, this literature yielded mixed results with the most cohesive findings emerging for two life events that typically occur in young adulthood (Bleidorn et al., 2018). First, research consistently finds that the first romantic relationship is related to increases in emotional stability and extraversion (Neyer \& Lehnart, 2007; Wagner et al., 2015). Second, the transition from school to college or work has been repeatedly associated with increases in agreeableness, conscientiousness, openness, and decreases in neuroticism (Bleidorn, 2012; Lüdtke et al., 2011). Evidence for the impact of other major life events, such as marriage or retirement, is less consistent and even the literature on major traumatic events provides no consistent evidence for effects on personality trait change (Mangelsdorf et al., 2019). For example, many might consider the birth of the first child as a turning point or transformational experience with a potential to interrupt, redirect, and change priorities and personalities of the parents. However, evidence for the effects of parenthood on personality trait change is more mixed than one would expect given the psychological importance of this life transition. Indeed, prospective studies that compared new parents' Big Five trajectories with those of relevant comparison groups found little evidence for effects of parenthood on Big Five personality trait change (Denissen et al., 2019; van Scheppingen et al., 2016).

The mixed evidence for main effects of life events on personality trait change may partly reflect methodological complexities that we will lay out in more detail below. 
More importantly, however, we believe and have recently argued that the focus on main effects of single, isolated life events on personality trait change is problematic. The implicit assumption that life events would provoke the same trait changes in most people - independent of their particular psychological background, environmental context, and life circumstances - may be too simplified, as it neglects important complexities in the ways people's life trajectories unfold in the context of environmental experiences (Bleidorn et al., 2020). Many life events, such as marriage and divorce, are correlated and tend to occur in predictable sequences. An isolated focus on individual life events is thus difficult to achieve and possibly misleading (Luhmann et al., 2020). Moreover, the same life events may elicit different responses in different people and at different timescales depending on people's contextual and psychological situation. Indeed, there is growing evidence that the degree to which life events elicit changes in people's personality traits varies from person to person (Denissen et al., 2019).

In summary, there is overall agreement that both genetic and environmental factors contribute to stability and change in personality traits. However, questions concerning the influence of specific genes or environments remain largely unanswered. Theory and research have yet to account for the complex ways in which persons and environments interact to produce stable or changing patterns of thoughts, feelings, strivings, and behavior. These interactions should be specified in evidence-based integrative models of genetic and environmental sources of personality trait development (Wagner et al., 2020).

\section{How Do Personality Trait Changes Unfold?}

Knowledge about the processes by which personality traits change is critical for an understanding of personality trait development. Several theoretical frameworks have begun to address this question, all of which define personality processes as a series of interconnected steps through which a person's traits are either changed or stabilized (e.g., Baumert et al., 2017; Geukes et al., 2018; Hennecke et al., 2014; Wrzus \& Roberts, 2017). These accounts differ in their emphasis on different aspects of personality change processes; however, they all rest on the distinction between latent personality traits and their manifestations, often referred to as states. The expression of new or modified personality-relevant states, if sufficiently repeated, is thought to condense into habits, generalize across domains, and eventually lead to lasting trait changes (Bleidorn et al., 2020). This kind of process can be explicit or implicit. For instance, many people desire to be more conscientious (Hudson \& Fraley, 2015), and some people may actually be able to effectively change their momentary state levels of thoughts, feelings, strivings, and behaviors that are relevant for conscientiousness. Over time, consistently modified emotional, behavioral, motivational or cognitive states may turn into habits and generalize to a broader range of situations. Such volitional changes in different personality state modalities (i.e., thoughts, behaviors, strivings, and feelings) may reinforce each other in a corresponsive fashion, which may eventually lead to lasting trait changes. 
Although research on personality processes is flourishing (e.g., Back, in press), this work needs to be better connected with longitudinal research on personality trait development (Geukes et al., 2018; Wrzus \& Roberts, 2017). One reason for the scarcity of longitudinal research on personality change processes is that personality process research is cost- and data-intensive. Rigorous process studies require frequent or even continuous assessments of people's thoughts, feelings, strivings, and behaviors over long periods of time and/or in response to theoretically relevant triggering situations.

\section{New Directions in Research on Personality Trait Stability and Change}

The field has made important progress in describing personality trait stability and change across the lifespan. However, several questions about the sources and processes of personality trait development remain. New theoretical advances and collaborative research efforts will be critical to move the field forward towards a better understanding of the mechanics of personality trait development. We envision a paradigmatic shift towards more collaborative research with teams of investigators who join expertise, skills, and resources in order to address the next generation of research questions about personality trait development. As we will outline next, we see the most pressing questions in four areas of research - time, samples, measures, and causality.

\section{Time}

At what time scale do personality trait changes unfold? What is the normative rate of change across the lifespan? And how long does it take for trait changes to manifest in response to life experiences? Answers to these and related questions are critical for a better understanding of the process of personality trait development.

Ideally, the number, frequency, and timing of assessments in studies about personality trait development should be closely matched to a well-specified theory about the process underlying development (Hopwood et al., in press). These parameters would, in turn, constrain the types of analyses that can be conducted and the inferences that can be drawn from the data (Luhmann et al., 2014). However, personality scientists often face less than ideal conditions when working with existing longitudinal data or designing new longitudinal studies. Indeed, it is common practice to analyze existing longitudinal data that were not necessarily collected with research questions about personality trait development in mind (e.g., Graham et al., 2020). Many longitudinal studies are designed under the assumption that personality traits are highly stable and thus include relatively few personality assessments that are often too widely spaced to allow researchers to study personality change with the necessary temporal resolution (Bleidorn et al., 2020). 
Likewise, theories of personality trait development are often not sufficiently developed to make exact predictions about longitudinal processes. In the absence of strong theories about the process of personality change, a better understanding of the rate and timing of personality change can only be achieved through longitudinal studies that include multiple assessments of personality, personality-relevant states (i.e., experiences and behaviors in the moment), and outcomes at different frequencies. Given that we know very little about when and how changes in traits unfold, longitudinal studies with more frequent - or even continuous - assessments with sufficiently short lags between assessments are needed to learn more about the pace and timing of personality trait change (Luhmann et al., 2014).

A high temporal resolution of assessments may be particularly important during periods when trait change is anticipated, for example during major life transitions or in the context of an intervention study (Bleidorn et al., 2020). A viable strategy to increase the frequency of assessments during such periods is the inclusion of measurement burst periods into longitudinal designs (Wrzus \& Mehl, 2015). For example, researchers interested in personality trait change in romantic relationships may time their assessments in reference to theoretically relevant events, such as marriage or parenthood, or in response to certain recurring experiences such as marital conflicts or daily hassles.

But what if such studies are not feasible? Alternatively, or in addition to collecting new data, researchers can use analytic approaches to explicitly model the timing of personality trait change. For example, continuous time models (Voelkle et al., 2012) show some promise for testing how the direction and strength of within-person associations between personality states and traits vary as a function of differing time intervals (e.g., over days, weeks, months, years, decades).

\section{Samples}

How generalizable are findings about personality trait development? The vast majority of studies on personality trait development has utilized data collected in Western, educated, industrialized, rich, and democratic (WEIRD; Henrich et al., 2010) countries in Western Europe and North America, and may thus not generalize to other populations. Very few studies have explored cultural differences in personality trait development (e.g., Bleidorn et al., 2013); and these studies have typically used cross-sectional designs to examine age differences in trait scores. However, a systematic examination of cultural differences in personality trait development has yet to be done. Such an analysis would not only be a crucial test of the generalizability of existing findings but would also provide important information about universal and culture-specific mechanisms underlying stability and change in personality traits.

A key challenge for such studies is the cross-cultural assessment of personality traits. Traditionally, personality assessment methods were developed and standardized exclusively in WEIRD samples. In many cases, these methods are not optimal in non-WEIRD 
settings because of different communication and privacy mores, familiarity with questionnaires, and issues related to language (Thalmayer \& Saucier, 2014). However, recent research efforts have broken ground in assessing personality differences in non-WEIRD countries (Thalmayer et al., 2020). So far, these works have relied on cross-sectional designs. Longitudinal studies are needed to track personality trait changes in samples from non-WEIRD cultures.

\section{Measurement}

Can we detect personality trait change in measures other than self-report? Self-report measures dominate research on personality traits. A broader set of tools for assessing personality differences and potential environmental influences across various timescales will be critical for moving the field forward towards a more comprehensive understanding of the sources and processes of personality trait stability and change (Bleidorn et al., 2020). We highlight three pressing issues that need to be addressed to advance the measurement of personality trait development.

First, the over-reliance on self-report measures limits the conclusions that can be drawn from existing research on personality stability and change (Back \& Egloff, 2009). In addition to the general limitations of monomethod research, there are several issues that specifically compromise the assessment of personality trait change using self-report questionnaires. Virtually all personality trait measures have been developed in cross-sectional data to capture the (presumably stable) structure of individual differences. We know little about the suitability of these measures for capturing the structure of intraindividual changes, or to measure personality processes (Horstmann \& Ziegler, 2020). Moreover, to the degree that people systematically compare their behavior to those of certain reference groups when processing self-report items (e.g., younger vs. older people), researchers may over- or underestimate change in personality traits (Credé et al., 2010). Longitudinal multi-trait multi-method studies are needed to address questions about validity and generalizability of existing longitudinal self-report findings. In addition to probing the convergent validity of measures of personality trait change, the observation of discrepancies between different assessment methods may lead to new insights regarding the sources and processes of personality trait change.

Second, the field lacks instruments that are explicitly tailored to the assessment of different personality state modalities (e.g., emotional, behavioral, motivational, cognitive) over time (Wrzus \& Mehl, 2015; Zimmermann et al., 2019). Existing research has mostly relied on broad self-report state measures; however, little research exists that tracked momentary behaviors or more implicit mental states over longer periods of time. Recent technological advancements such as mobile sensing and ambulatory assessment offer promising avenues for such high-resolution state measures and should be used to track changes along self-reported state changes (Bleidorn et al., 2020). 
A third issue is the lack of validated measures of environmental influences and life events. In addition to assessing the relatively objective occurrence of events, it will be important to capture people's subjective experience of events (Luhmann et al., 2020; Rauthmann et al., 2015; Wagner et al., 2020). Some factors - such as valence or predictability - have been studied in isolation, but a more comprehensive perspective on the psychological ingredients of life events and their role in personality trait development is needed. Individuals' subjective perceptions of events may yield critical information for understanding when and how life experiences affect personality traits. Measuring these perceptions in longitudinal samples alongside more objective measures of life events will provide important insights into potential sources of individual differences in personality trait change.

\section{Causality}

What causes personality trait change? As with most areas in personality science, correlational studies dominate research on personality trait development. Correlational - and particularly longitudinal - studies have led to important insights about the stability of and change in personality traits across the lifespan. However, as any single study design, correlational studies - even if longitudinal - are limited in their ability to inform questions about the causes of personality trait change (Schwaba et al., 2021; VanderWeele \& Ding, 2017). To address questions about causality, correlational studies should be complemented by research designs that can strengthen causal conclusions, such as randomized interventions and studies of natural experiments.

\section{Intervention Designs}

Between-person randomized controlled trials (RCTs) and intervention designs are routinely used in clinical psychology and medical sciences to examine whether a certain outcome variable can be changed through a specific treatment protocol. Although few studies have tested the effects of clinical interventions on change in personality traits directly, many studies have assessed change in personality traits as a secondary outcome. A recent meta-analysis of this literature suggests that clinical interventions can lead to lasting changes in personality traits, sometimes substantially and rather quickly (Roberts et al., 2017). In contrast to the rich literature on clinical interventions, research on non-clinical personality interventions has only recently taken root in personality science. This line of work - although still in its infancy - has found promising effects of various intervention techniques, including goal setting, behavioral activation, coaching, and smartphone-based interventions (Bleidorn et al., 2019).

For example, research on volitional personality change has highlighted the role of change goals, people's desires to change specific personality traits (Hudson \& Fraley, 2015; Hudson et al., 2020). Indeed, Hudson et al. (2020) found that change goals predict change in all Big Five traits. Change goals alone, however, may be necessary but not 
sufficient for achieving change. Recent intervention studies indicate that effective change in trait levels requires people to actively engage in tasks and challenges that pull their behavior in the direction of the desired trait levels (Hudson et al., 2019; Stieger et al., 2021). Notably, these and other personality intervention studies have typically followed participants over relatively short-time periods, ranging from 10 weeks to maximal 6 months. It thus remains an open question whether the observed changes reflect a temporary accentuation of trait levels as a result of the intervention or indeed lasting changes that remain stable over longer periods of time. Long-term follow ups are needed to examine and validate intervention protocols designed to target different traits in different populations across longer time periods.

\section{Natural Experiments}

Natural experiments allow researchers to examine the effects of exogeneous shocks - defined as unexpected or unpredictable events that are outside of the participants' and researcher's control - on psychological variables while ruling out third-variable or reverse causality explanations (Akee et al., 2018). Major collective events such as natural disasters (e.g., Damian et al., 2021) create natural experiments because they meet the aforementioned criteria and affect many people at once. For example, recent studies have begun to examine the effects of the Covid-19 pandemic on changes in personality traits and well-being (e.g., Sutin et al., 2020). Exploiting the unforeseen nature of the pandemic, such studies examine differences in personality levels before and after the outbreak of the pandemic to establish the causal effects of this crisis on personality trait change.

In another recent study, Schwaba et al. (2021) examined the effects of childhood lead exposure on adult personality differences in a natural experiment. Using data from over 1.5 million people, they found that US and European residents who grew up in areas with higher levels of atmospheric lead had less adaptive personality profiles in adulthood (lower conscientiousness, lower agreeableness, and higher neuroticism). Crucially, reductions of leaded gasoline in the US following the 1970 Clean Air Act corresponded with regional increases in psychologically healthy personality traits, suggesting that even low-level lead exposure may adversely impact personality traits.

\section{Conclusion}

Over the past few decades, research on personality trait development has pushed the field towards a better understanding of traits as both moderately stable and malleable constructs that can and do change across the lifespan and in response to certain experiences. Open questions remain about the specific sources that drive changes in traits and little is known about the processes underlying such changes. We believe and have recently argued (Bleidorn et al., 2019, 2020) that progress in the field of personality trait development requires more rigorous research designs featuring assessments of multiple 
potential sources of change related to the person, their genes, and their environments; large, diverse, and representative samples; specific theoretical models of processes that underlie personality change; frequent, multi-method assessments; and embedded experimental or burst designs targeting specific mechanisms. The success of such studies will depend on collaborative efforts of researchers who join resources and expertise. Funding for such studies and their ultimate impact will also be more likely to the degree that personality psychologists are able to join forces and publicize the importance of personality trait change to a broader audience. In establishing the Personality Change Consortium (PCC) - a consortium for the study of personality change - we aim to promote such efforts and contribute to transformative personality research that advances theory and public welfare.

Funding: The authors have no funding to report.

Acknowledgments: The authors have no additional (i.e., non-financial) support to report.

Competing Interests: The authors have declared that no competing interests exist.

Author Contributions: Wiebke Bleidorn-Idea, conceptualization | Writing. Christopher f. Hopwood-Feedback, revisions. Mitja D. Back-Feedback, revisions. Jaap f. A. Denissen-Feedback, revisions. Marie Hennecke-Feedback, revisions. Patrick L. Hill-Feedback, revisions. Markus fokela-Feedback, revisions. Christian Kandler-Feedback, revisions. Richard E. Lucas-Feedback, revisions. Maike Luhmann-Feedback, revisions. Ulrich Orth-Feedback, revisions. Brent W. Roberts-Feedback, revisions. Jenny Wagner-Feedback, revisions. Cornelia Wrzus-Feedback, revisions. Johannes Zimmermann-Feedback, revisions.

Ethics Statement: No ethical issues and/or ethics approvals need to be disclosed.

Related Versions: No other previously published versions of this manuscript exist in part or in whole.

Author Note: The authors are members of the Personality Change Consortium (PCC).

\section{References}

Akee, R., Copeland, W., Costello, E. J., \& Simeonova, E. (2018). How does household income affect child personality traits and behaviors? The American Economic Review, 108(3), 775-827. https://doi.org/10.1257/aer.20160133

Allport, G. W. (1961). Pattern and growth in personality. Holt, Reinhart \& Winston.

Ashton, M. C., \& Lee, K. (2020). Objections to the HEXACO model of personality structure-And why those objections fail. European fournal of Personality, 34(4), 492-510.

https://doi.org/10.1002/per.2242

Back, M. D. (in press). Social interaction processes and personality. The handbook of personality dynamics and processes, Elsevier. https://doi.org/10.31234/osf.io/evm4n 
Back, M. D., \& Egloff, B. (2009). Yes we can! A plea for direct behavioral observation in personality research. European fournal of Personality, 23, 403-405.

Baumert, A., Schmitt, M., Perugini, M., Johnson, W., Blum, G., Borkenau, P., Costantini, G., Denissen, J. J. A., Fleeson, W., Grafton, B., Jayawickreme, E., Kurzius, E., MacLeod, C., Miller, L. C., Read, S. J., Roberts, B., Robinson, M. D., Wood, D., \& Wrzus, C. (2017). Integrating personality structure, personality process, and personality development. European fournal of Personality, 31(5), 503-528. https://doi.org/10.1002/per.2115

Bleidorn, W. (2012). Hitting the road to adulthood: Short-term personality development during a major life transition. Personality and Social Psychology Bulletin, 38(12), 1594-1608. https://doi.org/10.1177/0146167212456707

Bleidorn, W., Hill, P. L., Back, M. D., Denissen, J. J. A., Hennecke, M., Hopwood, C. J., Jokela, M., Kandler, C., Lucas, R. E., Luhmann, M., Orth, U., Wagner, J., Wrzus, C., Zimmermann, J., \& Roberts, B. W. (2019). The policy relevance of personality traits. The American Psychologist, 74(9), 1056-1067. https://doi.org/10.1037/amp0000503

Bleidorn, W., Hopwood, C. J., Back, M. D., Denissen, J. J. A., Hennecke, M., Jokela, M., Kandler, C., Lucas, R. E., Luhmann, M., Orth, U., Roberts, B. W., Wagner, J., Wrzus, C., \& Zimmermann, J. (2020). Longitudinal Experience-Wide Association Studies (LEWAS) - A framework for studying personality change. European fournal of Personality, 34(3), 285-300. https://doi.org/10.1002/per.2247

Bleidorn, W., Hopwood, C. J., \& Lucas, R. E. (2018). Life events and personality trait change. fournal of Personality, 86(1), 83-96. https://doi.org/10.1111/jopy.12286

Bleidorn, W., Klimstra, T. A., Denissen, J. J. A., Rentfrow, P. J., Potter, J., \& Gosling, S. D. (2013). Personality maturation around the world: A cross-cultural examination of Social Investment Theory. Psychological Science, 24(12), 2530-2540. https://doi.org/10.1177/0956797613498396

Briley, D. A., \& Tucker-Drob, E. M. (2014). Genetic and environmental continuity in personality development: A meta-analysis. Psychological Bulletin, 140(5), 1303-1331. https://doi.org/10.1037/a0037091

Costa, P. T., Jr., McCrae, R. R., \& Löckenhoff, C. E. (2019). Personality across the life span. Annual Review of Psychology, 70(1), 423-448. https://doi.org/10.1146/annurev-psych-010418-103244

Credé, M., Bashshur, M., \& Niehorster, S. (2010). Reference group effects in the measurement of personality and attitudes. Journal of Personality Assessment, 92(5), 390-399. https://doi.org/10.1080/00223891.2010.497393

Damian, R. I., Serrano, S., \& Hill, P. L. (2021). Hurricane exposure and personality development. fournal of Personality, 89(1), 35-49. https://doi.org/10.1111/jopy.12542

Damian, R. I., Spengler, M., Sutu, A., \& Roberts, B. W. (2019). Sixteen going on sixty-six: A longitudinal study of personality stability and change across 50 years. Fournal of Personality and Social Psychology, 117(3), 674-695. https://doi.org/10.1037/pspp0000210

Denissen, J. J. A., Luhmann, M., Chung, J. M., \& Bleidorn, W. (2019). Transactions between life events and personality traits across the adult lifespan. Journal of Personality and Social Psychology, 116(4), 612-633. https://doi.org/10.1037/pspp0000196 
Denissen, J. J., van Aken, M. A., Penke, L., \& Wood, D. (2013). Self-regulation underlies temperament and personality: An integrative developmental framework. Child Development Perspectives, 7(4), 255-260. https://doi.org/10.1111/cdep.12050

Fraley, R. C., \& Roberts, B. W. (2005). Patterns of continuity: A dynamic model for conceptualizing the stability of individual differences in psychological constructs across the life course. Psychological Review, 112(1), 60-74. https://doi.org/10.1037/0033-295X.112.1.60

Geukes, K., van Zalk, M., \& Back, M. D. (2018). Understanding personality development: An integrative state process model. International fournal of Behavioral Development, 42(1), 43-51. https://doi.org/10.1177/0165025416677847

Graham, E. K., Weston, S. J., Gerstorf, D., Yoneda, T. B., Booth, T., Beam, C. R., Petkus, A. J., Drewelies, J., Hall, A. N., Bastarache, E. D., Estabrook, R., Katz, M. J., Turiano, N. A., Lindenberger, U., Smith, J., Wagner, G. G., Pedersen, N. L., Allemand, M., Spiro, A. III, Deeg, D. J. H., Johansson, B., Piccinin, A. M., Lipton, R. B., Schaie, K. W., Willis, S., Reynolds, C. A., Deary, I. J., Hofer, S. M., \& Mroczek, D. K. (2020). Trajectories of Big Five personality traits: A coordinated analysis of 16 longitudinal samples. European fournal of Personality, 34(3), 301-321. https://doi.org/10.1002/per.2259

Hennecke, M., Bleidorn, W., Denissen, J. J. A., \& Wood, D. (2014). A three-part framework for selfregulated personality development across adulthood. European fournal of Personality, 28(3), 289-299. https://doi.org/10.1002/per.1945

Henrich, J., Heine, S. J., \& Norenzayan, A. (2010). Most people are not WEIRD. Nature, 466, Article 29. https://doi.org/10.1038/466029a

Hopwood, C. J., Bleidorn, W., \& Wright, A. G. C. (in press). Connecting theory to methods in longitudinal research. Perspectives on Psychological Science. https://doi.org/10.31234/osf.io/w5huz

Horstmann, K., \& Ziegler, M. (2020). Assessing personality states: What to consider when constructing personality state measures. European fournal of Personality, 34(6), 1037-1059. https://doi.org/10.1002/per.2266

Hudson, N. W., Briley, D. A., Chopik, W. J., \& Derringer, J. (2019). You have to follow through: Attaining behavioral change goals predicts volitional personality change. fournal of Personality and Social Psychology, 117(4), 839-857. https://doi.org/10.1037/pspp0000221

Hudson, N. W., \& Fraley, R. C. (2015). Volitional personality trait change: Can people choose to change their personality traits? fournal of Personality and Social Psychology, 109(3), 490-507. https://doi.org/10.1037/pspp0000021

Hudson, N. W., Fraley, R. C., Chopik, W. J., \& Briley, D. A. (2020). Change goals robustly predict trait growth: A mega-analysis of a dozen intensive longitudinal studies examining volitional change. Social Psychological \& Personality Science, 11(6), 723-732. https://doi.org/10.1177/1948550619878423

John, O. P., \& Srivastava, S. (1999). The Big Five trait taxonomy: History, measurement, and theoretical perspectives. In L. A. Pervin \& O. P. John (Eds.), Handbook of personality: Theory and research (2nd ed., pp. 102-138). Guilford. 
Kandler, C., Bleidorn, W., Riemann, R., Spinath, F. M., Thiel, W., \& Angleitner, A. (2010). Sources of cumulative continuity in personality: A longitudinal multiple-rater twin study. Journal of Personality and Social Psychology, 98(6), 995-1008. https://doi.org/10.1037/a0019558

Kandler, C., Kornadt, A. E., Hagemeyer, B., \& Neyer, F. J. (2015). Patterns and sources of personality development in old age. Journal of Personality and Social Psychology, 109(1), 175-191. https://doi.org/10.1037/pspp0000028

Lucas, R. E., \& Donnellan, M. B. (2011). Personality development across the life span: Longitudinal analyses with a national sample from Germany. Journal of Personality and Social Psychology, 101(4), 847-861. https://doi.org/10.1037/a0024298

Lüdtke, O., Roberts, B. W., Trautwein, U., \& Nagy, G. (2011). A random walk down university avenue: Life paths, life events, and personality trait change at the transition to university life. fournal of Personality and Social Psychology, 101(3), 620-637. https://doi.org/10.1037/a0023743

Luhmann, M., Fassbender, I., Alcock, M., \& Haehner, P. (2020). A dimensional taxonomy of perceived characteristics of major life events. Journal of Personality and Social Psychology; Advance online publication. https://doi.org/10.1037/pspp0000291

Luhmann, M., Orth, U., Specht, J., Kandler, C., \& Lucas, R. E. (2014). Studying changes in life circumstances and personality: It's about time. European fournal of Personality, 28(3), 256-266. https://doi.org/10.1002/per.1951

Mangelsdorf, J., Eid, M., \& Luhmann, M. (2019). Does growth require suffering? A systematic review and meta-analysis on genuine posttraumatic and postecstatic growth. Psychological Bulletin, 145(3), 302-338. https://doi.org/10.1037/bul0000173

McAdams, D. P., Shiner, R. L., \& Tackett, J. L. (Eds.). (2018). Handbook of personality development. Guilford Press.

McCrae, R. R., \& Costa, P. (2008). The Five-Factor Theory of Personality. In O. P. John, R. W. Robins \& L. A. Pervin (Eds.), Handbook of personality: Theory and research (3rd ed., pp. 1-58). Guilford Press.

Mõttus, R., Johnson, W., \& Deary, I. J. (2012). Personality traits in old age: Measurement and rankorder stability and some mean-level change. Psychology and Aging, 27(1), 243-249. https://doi.org/10.1037/a0023690

Neyer, F. J., \& Lehnart, J. (2007). Relationships matter in personality development: Evidence from an 8-year longitudinal study across young adulthood. fournal of Personality, 75(3), 535-568. https://doi.org/10.1111/j.1467-6494.2007.00448.x

Ozer, D. J., \& Benet-Martinez, V. (2006). Personality and the prediction of consequential outcomes. Annual Review of Psychology, 57, 401-421. https://doi.org/10.1146/annurev.psych.57.102904.190127

Rauthmann, J. F., Sherman, R. A., \& Funder, D. C. (2015). Principles of situation research: Towards a better understanding of psychological situations. European fournal of Personality, 29(3), 363-381. https://doi.org/10.1002/per.1994 
Roberts, B. W., \& DelVecchio, W. F. (2000). The rank-order consistency of personality traits from childhood to old age: a quantitative review of longitudinal studies. Psychological Bulletin, 126(1), 3-25. https://doi.org/10.1037/0033-2909.126.1.3

Roberts, B. W., Kuncel, N. R., Shiner, R., Caspi, A., \& Goldberg, L. R. (2007). The power of personality: The comparative validity of personality traits, socioeconomic status, and cognitive ability for predicting important life outcomes. Perspectives on Psychological Science, 2(4), 313-345. https://doi.org/10.1111/j.1745-6916.2007.00047.x

Roberts, B. W., Luo, J., Briley, D. A., Chow, P. I., Su, R., \& Hill, P. L. (2017). A systematic review of personality trait change through intervention. Psychological Bulletin, 143(2), 117-141. https://doi.org/10.1037/bul0000088

Roberts, B. W., Walton, K., \& Viechtbauer, W. (2006). Patterns of mean-level change in personality traits across the life course: A meta-analysis of longitudinal studies. Psychological Bulletin, 132(1), 1-25. https://doi.org/10.1037/0033-2909.132.1.1

Schwaba, T., \& Bleidorn, W. (2018). Individual differences in personality change across the adult lifespan. Journal of Personality, 86(3), 450-464. https://doi.org/10.1111/jopy.12327

Schwaba, T., Bleidorn, W., Hopwood, C. J., Rentfow, P. J., Gebauer, J. E., Potter, J., \& Gosling, S. D. (2021). The impact of childhood lead exposure on adult personality: Evidence from the US, Europe, and a large-scale natural experiment [Manuscript submitted for publication].

Soto, C. J. (2016). The Little Six personality dimensions from early childhood to early adulthood: Mean-level age and gender differences in parents' reports. fournal of Personality, 84(4), 409-422. https://doi.org/10.1111/jopy.12168

Soto, C. J. (2021). Do links between personality and life outcomes generalize? Testing the robustness of trait-outcome associations across gender, age, ethnicity, and analytic approaches. Social Psychological \& Personality Science, 12(1), 118-130.

https://doi.org/10.1177/1948550619900572

Soto, C. J., \& Tackett, J. L. (2015). Personality traits in childhood and adolescence: Structure, development, and outcomes. Current Directions in Psychological Science, 24(5), 358-362. https://doi.org/10.1177/0963721415589345

Specht, J. (Ed.). (2017). Personality development across the lifespan. Academic Press.

Specht, J., Bleidorn, W., Denissen, J. J. A., Hennecke, M., Hutteman, R., Kandler, C., Luhmann, M., Orth, U., Reitz, A., \& Zimmermann, J. (2014). What drives adult personality development? A comparison of theories and empirical evidence. European fournal of Personality, 28(3), 216-230. https://doi.org/10.1002/per.1966

Stieger, M., Flückiger, C., Rüegger, D., Kowatsch, T., Roberts, B. W., \& Allemand, M. (2021). Changing personality traits with the help of a digital personality change intervention. Proceedings of the National Academy of Sciences of the United States of America, 118(8), Article e2017548118. https://doi.org/10.1073/pnas.2017548118

Sutin, A. R., Luchetti, M., Aschwanden, D., Lee, J. H., Sesker, A. A., Strickhouser, J. E., Stephan, Y., \& Terracciano, A. (2020). Change in five-factor model personality traits during the acute phase of 
the coronavirus pandemic. PLOS ONE, 15(8), Article e0237056.

https://doi.org/10.1371/journal.pone.0237056

Thalmayer, A. G., \& Saucier, G. (2014). The questionnaire big six in 26 nations: Developing crossculturally applicable big six, big five and big two inventories. European fournal of Personality, 28(5), 482-496. https://doi.org/10.1002/per.1969

Thalmayer, A. G., Saucier, G., Ole-Kotikash, L., \& Payne, D. (2020). Personality structure in east and west Africa: Lexical studies of personality in Maa and Supyire-Senufo. Journal of Personality and Social Psychology; Advance online publication. https://doi.org/10.1037/pspp0000264

VanderWeele, T. J., \& Ding, P. (2017). Sensitivity analysis in observational research: Introducing the E-value. Annals of Internal Medicine, 167(4), 268-274. https://doi.org/10.7326/M16-2607

van Scheppingen, M. A., Jackson, J. J., Specht, J., Hutteman, R., Denissen, J. J. A., \& Bleidorn, W. (2016). Personality trait development during the transition to parenthood: A test of social investment theory. Social Psychological \& Personality Science, 7(5), 452-462. https://doi.org/10.1177/1948550616630032

Voelkle, M. C., Oud, J. H. L., Davidov, E., \& Schmidt, P. (2012). An SEM approach to continuous time modeling of panel data: Relating authoritarianism and anomia. Psychological Methods, 17(2), 176-192. https://doi.org/10.1037/a0027543

Wagner, J., Becker, M., Lüdtke, O., \& Trautwein, U. (2015). The first partnership experience and personality development: A propensity score matching study in young adulthood. Social Psychological \& Personality Science, 6(4), 455-463. https://doi.org/10.1177/1948550614566092

Wagner, J., Orth, U., Bleidorn, W., Hopwood, C., \& Kandler, C. (2020). Towards an integrative model of sources of personality stability and change. Current Directions in Psychological Science, 29(5), 438-444. https://doi.org/10.1177/0963721420924751

Wright, A. G. C., Hopwood, C. J., \& Zanarini, M. C. (2015). Associations between changes in normal personality traits and borderline personality disorder symptoms over 16 years. Personality Disorders, 6(1), 1-11. https://doi.org/10.1037/per0000092

Wrzus, C., \& Mehl, M. R. (2015). Lab and/or field? Measuring personality processes and their social consequences. European fournal of Personality, 29(2), 250-271. https://doi.org/10.1002/per.1986

Wrzus, C., \& Roberts, B. W. (2017). Processes of personality development in adulthood: The TESSERA framework. Personality and Social Psychology Review, 21(3), 253-277. https://doi.org/10.1177/1088868316652279

Zimmermann, J., Woods, W. C., Ritter, S., Happel, M., Masuhr, O., Jaeger, U., Spitzer, C., \& Wright, A. G. C. (2019). Integrating structure and dynamics in personality assessment: First steps toward the development and validation of a Personality Dynamics Diary. Psychological Assessment, 31(4), 516-531. https://doi.org/10.1037/pas0000625 


\section{eapp}

Personality Science (PS) is an official journal of the European Association of Personality Psychology (EAPP).
(P) leibniz-psychology.org

PsychOpen GOLD is a publishing service by Leibniz Institute for Psychology (ZPID), Germany. 